\title{
Research on deadbeat Current Control Strategy of Three-Phase PWM Voltage Source Rectifier
}

\author{
Quan WEN Ling ZHU Chao FU \\ The State Key Laboratory of Alternate Electrical Power System with Renewable Energy Sources \\ North China Electric Power University \\ Bao ding, China \\ E-mail: wenquan135@163.com
}

\begin{abstract}
Dynamic response slow and DC voltage fluctuation when traditional current inner loop controller based on dq transformation applications in three-phase PWM voltage source rectifier (VSR). To these shortcomings, firstly this paper established discrete mathematical model of VSR, derived deadbeat control strategies based on deadbeat control theory for VSR. Secondly, design a double-closed-loop controller with current inner loop and voltage outer loop for the system. Finally, set up a Matlab/Simulink simulation platform of three-phase PWM voltage source rectifier to verify the theoretical analysis results. The results show that the three-phase PWM voltage source rectifier based on the deadbeat control in stabilizing DC voltage, control the AC current, etc, it has good steady-state and dynamic performance. The control method is simple, easy to implement, and has a certain practical value.
\end{abstract}

Keywords-PWM rectifier; deadbeat control; dual closed-loop control

\section{INTRODUCTION}

Three-phase PWM voltage source rectifier (VSR) has such outstanding advantages as can not only output adjustable and stable de voltage, but also can adjust the input power factor, reduce the current harmonic distortion, energy can be two-way flow. Therefore, the control strategy of three-phase PWM voltage source rectifier became the focus of research.

Early PWM rectifier mainly uses the indirect current control, it indirect control input current through the control of rectifier's input voltage amplitude and phase. Its advantages is having no need of current sensor, but the disadvantages are slow dynamic response and do not have current limiting function [1]. Later the direct current control method bring in the current feedback, it has such advantages as quick dynamic response, easy current limiting and higher current control precision, etc [2]. There are many methods of direct current control: fixed switching frequency PWM current control [3], hysteretic current PWM control $[4,5]$ and deadbeat control. Fixed switching frequency PWM current control algorithm is simple, achievable and convenient, but in the condition when the switching frequency is not high, current dynamic response is slow, and the current dynamic deviation change with the current rate change accordingly. Hysteretic current PWM control has higher current response, but switching frequency is not fixed, lead to the grid side filter inductor hard to design and big power module loss, so make the circuit reliability decline. Deadbeat control was put forward by the famous American control theory expert Kalman, it has fast response, high precision and small distortion rate, etc [6].

Deadbeat control is a characteristic control mode of digital system, with the development of digital control technology, people began to use high-speed microprocessor numerical calculation function to realize full digital control mode. Deadbeat current control technology has faster dynamic response than other digital feedback control, and it can greatly improve the dynamic performance of rectifier. Therefore, it is necessary to discrete VSR of the mathematical model [7]. This paper deduced discrete mathematics model of VSR in dq0 coordinate system, established discrete deadbeat current controller, compared with the simulation-based on $\mathrm{dq}$ transformation of the traditional current controller, and verify that the proposed deadbeat control strategy is effective through the simulation.

\section{DISCRETIZATION MATHEMATICAL MODEL OF THREE- PHASE PWM VOLTAGE SOURCE RECTIFIER}

Three-phase voltage source PWM rectifier's topology is shown in Fig 1. Where: $e_{a}, e_{b}, e_{c}$ are three-phase voltage sources; $u_{a}, u_{b}, u_{c}$ are three-phase voltage for input side of VSR; $i_{a}, i_{b}, i_{c}$ are three-phase current of VSR, $L$ is the inductance of $\mathrm{AC}$ side ; $R$ is equivalent circuit resistance; $\mathrm{C}$ is DC side capacitor; $R_{\mathrm{dc}}$ is $\mathrm{DC}$ side equivalent load impedance; $u_{\mathrm{dc}}$ is DC voltage; $i_{\mathrm{dc}}$ is the current of DC system.

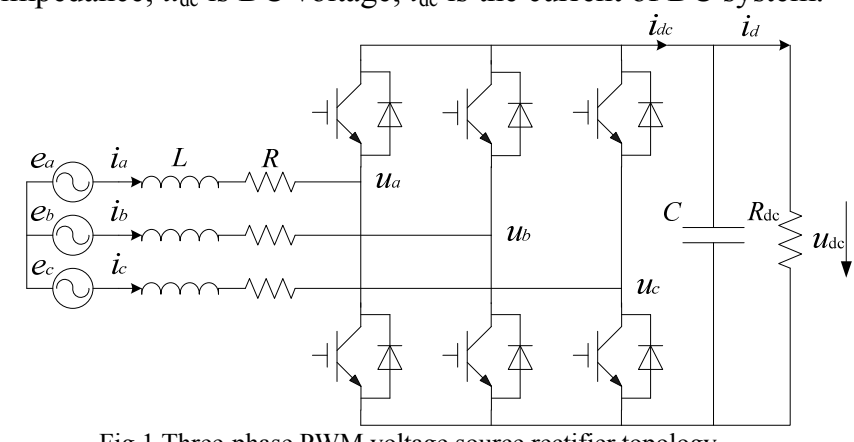

Fig.1 Three-phase PWM voltage source rectifier topology

According to Kirchhoff's law and base on the topology for VSR, we can get (1) in three -phase stationary coordinate system in matrix form 


$$
\left[\begin{array}{c}
\frac{d i_{a}}{d t} \\
\frac{d i_{b}}{d t} \\
\frac{d i_{c}}{d t}
\end{array}\right]=\left[\begin{array}{ccc}
-\frac{R}{L} & 0 & 0 \\
0 & -\frac{R}{L} & 0 \\
0 & 0 & -\frac{R}{L}
\end{array}\right]\left[\begin{array}{l}
i_{a} \\
i_{b} \\
i_{c}
\end{array}\right]+\frac{1}{L}\left[\begin{array}{l}
e_{a}-u_{a} \\
e_{b}-u_{b} \\
e_{c}-u_{c}
\end{array}\right]
$$

The mathematical model in three-phase coordinate system can be converted to the model in dq rotary coordinate system through $3 \mathrm{~s} / 2 \mathrm{r}$ coordinate transformation; the twophase mathematical model is showed in (2)

$$
\left[\begin{array}{l}
\frac{d i_{d}}{d t} \\
\frac{d i_{q}}{d t}
\end{array}\right]=\left[\begin{array}{cc}
-\frac{R}{L} & \omega \\
-\omega & -\frac{R}{L}
\end{array}\right]\left[\begin{array}{l}
i_{d} \\
i_{q}
\end{array}\right]+\frac{1}{L}\left[\begin{array}{l}
e_{d}-u_{d} \\
e_{q}-u_{q}
\end{array}\right]
$$

Where, $i_{d}, i_{q}$ are three-phase current of VSR in dq coordinate system; $e_{d}, e_{q}$ are three-phase voltage of grid in dq coordinate system; $u_{d}, u_{q}$ are three-phase voltage for input side of VSR in dq coordinate system.

To discretize (2), assume $T$ is the sampling period, from $k T$ to $(k+1) T$, using forward difference method, we can get equivalent power grid current differential value

$$
\left\{\begin{array}{l}
\frac{d i_{d}}{d t}=\left[i_{d}(k+1)-i_{d}(k)\right] / T \\
\frac{d i_{q}}{d t}=\left[i_{q}(k+1)-i_{q}(k)\right] / T
\end{array}\right.
$$

Assume that from $k T$ to $(k+1) T$, grid current can approximate average value; when PWM Switch frequency far outweigh the grid frequency, power grid voltage changes little in a sampling period, therefore, we can assume that power grid voltage unchanged in a sampling period. Linking (3) into (2), we can get (4), which is the discrete mathematical model of three-phase PWM VSR.

$$
\left\{\begin{aligned}
u_{d}(k+1)= & -L \frac{i_{d}(k+1)-i_{d}(k)}{T}-R \frac{i_{d}(k+1)+i_{d}(k)}{2} \\
& +\omega L \frac{i_{q}(k+1)+i_{q}(k)}{2}+e_{d}(k) \\
u_{q}(k+1)= & -L \frac{i_{q}(k+1)-i_{q}(k)}{T}-\omega L \frac{i_{d}(k+1)+i_{d}(k)}{2} \\
& -R \frac{i_{q}(k+1)+i_{q}(k)}{2}+e_{q}(k)
\end{aligned}\right.
$$

\section{THREE-PHASE VOLTAGE SOURCE PWM RECTIFIER CONTROL STRATEGY}

\section{A. The principle of deadbeat control}

Deadbeat control is defined as: at the beginning of each sampling period collect input current $i$ of PWM rectifier, then predict input current given value $i^{*}$ for the next sampling period through calculation. Calculate the switch tube conduction time from $i-i^{*}$, make sure $i=i^{*}$ at the beginning of the next sampling period.
From the definition we can see that deadbeat control is characteristic control mode of digital system. Although the calculate quantity of this method is big, its dynamic response is quick. With the development of computer technology, deadbeat control will be widely used in digital control system.

In fact, current sampling is in $k$ sampling period, the calculated current $i^{*}$ is reference state of $k$ sampling period, so the algorithm defined above can make the $k+1$ tracking the calculated reference value at $k$ sampling time. Therefore it can be described in (5) and (6)

$$
\begin{aligned}
& \left\{\begin{array}{l}
i_{d}(k+1)=i_{d}^{*}(k) \\
i_{q}(k+1)=i_{q}^{*}(k)
\end{array}\right. \\
& \left\{\begin{array}{l}
u_{d}(k+1)=u_{d}^{*}(k) \\
u_{q}(k+1)=u_{q}^{*}(k)
\end{array}\right.
\end{aligned}
$$

Where, $i_{d}{ }^{*}(k), i_{q}{ }^{*}(k)$ are current reference of VSR in dq rotary coordinate system, $u_{d}{ }^{*}(k), u_{q}{ }^{*}(k)$ are three-phase voltage for input side of VSR in dq rotary coordinate system.

According to the principle above, we can get (7), which is calculated command of voltage in deadbeat control.

$$
\left\{\begin{aligned}
u_{d}^{*}(k)= & -\left(\frac{L}{T}+\frac{R}{2}\right)\left[i_{d}^{*}(k)-i_{d}(k)\right] \\
& -R i_{d}(k)+\omega L \frac{i_{q}^{*}(k)+i_{q}(k)}{2}+e_{d}(k) \\
u_{q}^{*}(k)= & -\left(\frac{L}{T}+\frac{R}{2}\right)\left[i_{q}^{*}(k)-i_{q}(k)\right] \\
& -\omega L \frac{i_{d}^{*}(k)+i_{q}(k)}{2}-R i_{q}(k)+e_{q}(k)
\end{aligned}\right.
$$

\section{B. Deadbeat inner loop current controller design}

On the basis of the theoretical above, this paper presents the design of three-phase PWM VSR deadbeat control system. The control system is dual- closed-loop control structure which adopts outer voltage loop and inner current loop. Outer voltage loop is used to guarantee the stability of system, and inner current loop is used to improve the current rapid response.

In order to compensate voltage drop on reactive in the inverter, introducing PI controller. Then variant (7) to (8)

$$
\begin{aligned}
u_{d}^{*}(k)= & -\left\{K_{P}\left[i_{d}^{*}(k)-i_{d}(k)\right]+K_{I} \sum_{n=0}^{k}\left[i_{d}^{*}(n)-i_{d}(n)\right]\right\} \\
& +\omega L \frac{i_{q}^{*}(k)+i_{q}(k)}{2}+e_{d}(k) \\
u_{q}^{*}(k)= & -\left\{K_{P}\left[i_{q}^{*}(k)-i_{q}(k)\right]+K_{I} \sum_{n=0}^{k}\left[i_{q}^{*}(n)-i_{q}(n)\right]\right\} \\
& -\omega L \frac{i_{d}^{*}(k)+i_{q}(k)}{2}+e_{q}(k)
\end{aligned}
$$

From type (8) we can get inner current loop discrete controller of three-phase voltage source PWM rectifier shows in Fig.2. 


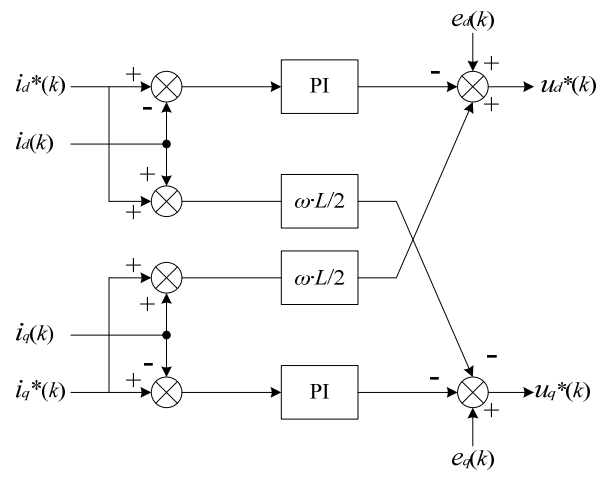

Fig.2 Schematic diagram of deadbeat inner-loop current discrete controller

The control equation of the formula (10) based on the dq transform traditional current inner control strategy

$$
\left\{\begin{array}{l}
u_{d}=-\left(K_{P}+\frac{K_{I}}{s}\right)\left(i_{d}^{*}-i_{d}\right)+\omega L i_{q}+e_{d} \\
u_{q}=-\left(K_{P}+\frac{K_{I}}{s}\right)\left(i_{q}^{*}-i_{q}\right)-\omega L i_{d}+e_{q}
\end{array}\right.
$$

According to equation (10) draw current inner loop controller block diagram as shown in Fig. 3

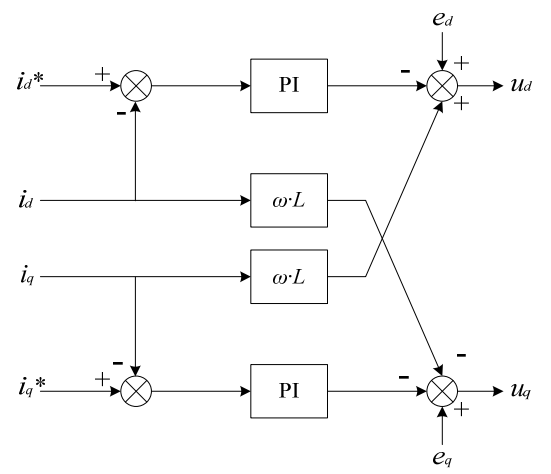

Fig.3 Schematic diagram of traditional inner-loop current controller

C. The design of Voltage outer loop controller

In Fig. $2 i_{d}^{*}(k), i_{q}^{*}(k)$ are given by outer loop. Ignore $R$, from the instantaneous power theory [8] get (10) in dq rotary coordinate system.

$$
\left\{\begin{array}{l}
P=\frac{3}{2}\left(e_{d} i_{d}+e_{q} i_{q}\right) \\
Q=\frac{3}{2}\left(e_{q} i_{d}-e_{d} i_{q}\right)
\end{array}\right.
$$

Under AC voltage balance conditions, take the d-axis direction and the $\mathrm{AC}$ voltage vector $e_{d}$ in the same direction, and the $\mathrm{AC}$ voltage can be written into $e_{d}=\mathrm{E}, e_{q}=0$. The power flow from $\mathrm{AC}$ grid to VSR can be described in (11):

$$
\left\{\begin{array}{c}
P=\frac{3}{2} e_{d} i_{d}^{*}(k) \\
Q=-\frac{3}{2} e_{d} i_{q}^{*}(k)
\end{array}\right.
$$

We assume that $R=0$, the rectifier $\mathrm{AC}$ and $\mathrm{DC}$ sides power maintain a balance, that is,

$$
P=\frac{3}{2} e_{d} i_{d}^{*}(k)=u_{\mathrm{dc}} i_{\mathrm{dc}}(k)
$$

When the system is stable, the DC side capacitor voltage differential value is 0 , i.e. $i_{\mathrm{dc}}(k)=i_{d}(k)$. In order to stabilize DC side voltage and to eliminate the steady state error of the controlled variable introduced digital PI controller. Fig. 4 is outer loop controller of three-phase PWM voltage source rectifier.

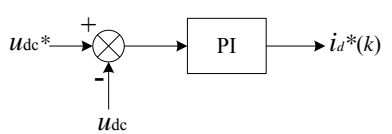

a. DC voltage outer loop

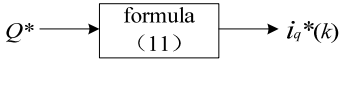

b. Reactive power outer loop
Fig.4 The outer loop discrete controller

\section{Simulation}

In order to verify the effectiveness of current deadbeat control strategy, two rectifier simulation models based on deadbeat current control strategy and traditional inner current loop control strategy are established respectively in Matlab/Simulink software platform. The model's parameter is set as follows: power grid phase-phase voltage's RMS is $400 \mathrm{~V} ; L=1 \mathrm{mH} ; \mathrm{C}=6000 ; \mathrm{U}_{\mathrm{dc}}{ }^{*}=500 \mathrm{~V}$; In order to ensure the input unity power factor, reactive power is given as 0 ; The switching frequency is $9 \mathrm{kHz} ; R_{\mathrm{dc}}=40 \Omega$.

For testing anti-jamming capability of rectifier at $1.5 \mathrm{~s}$ the $R_{\mathrm{dc}}$ change suddenly from 40 to $20 \Omega$. The simulation results are as follows

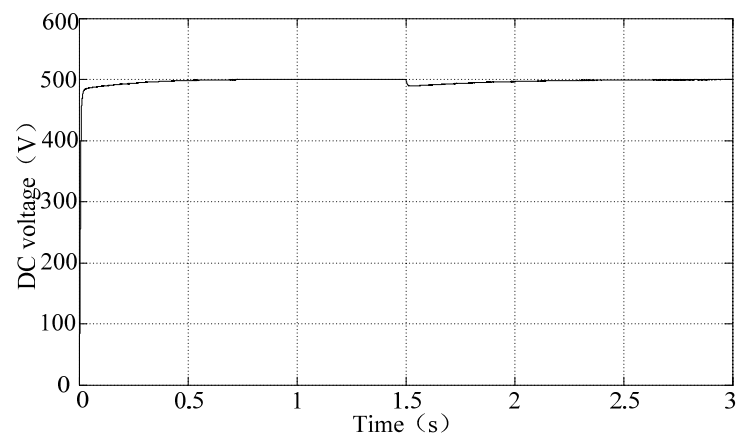

a. Traditional current control strategy

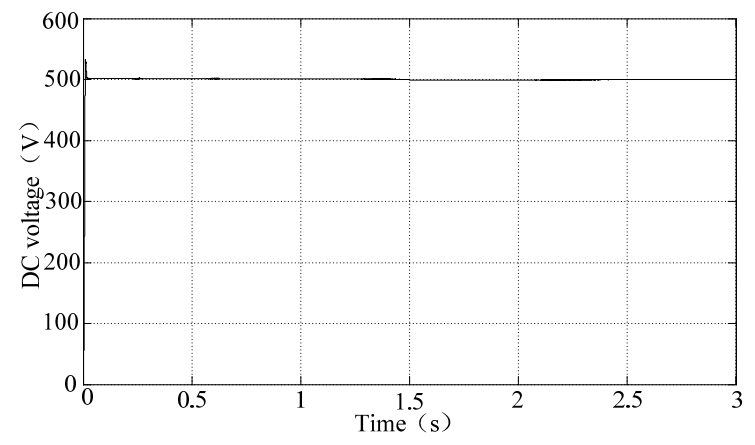

b. Deadbeat current control strategy

Fig.5 DC bus voltage 


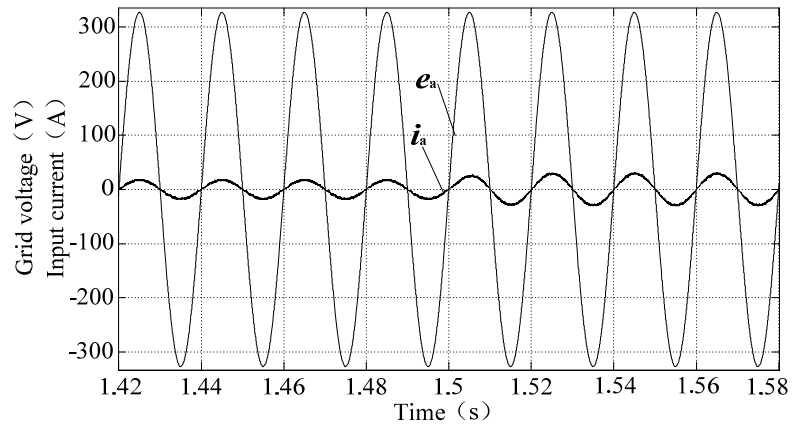

a. Traditional current control strategy

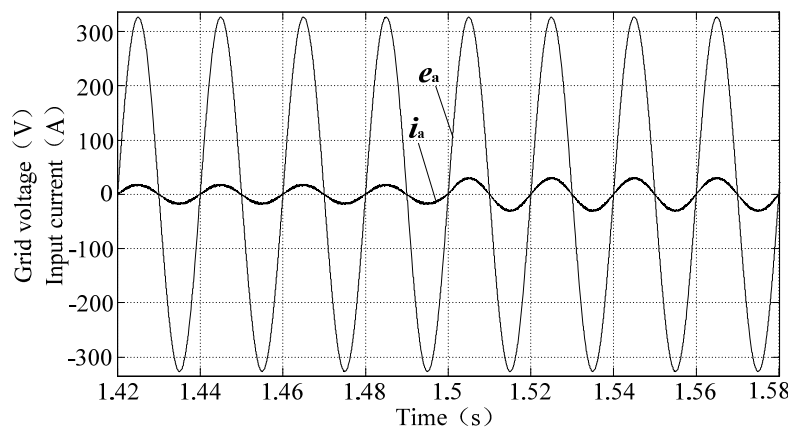

b. Deadbeat current control strategy

Fig.6 A-phase voltage and current of the AC side

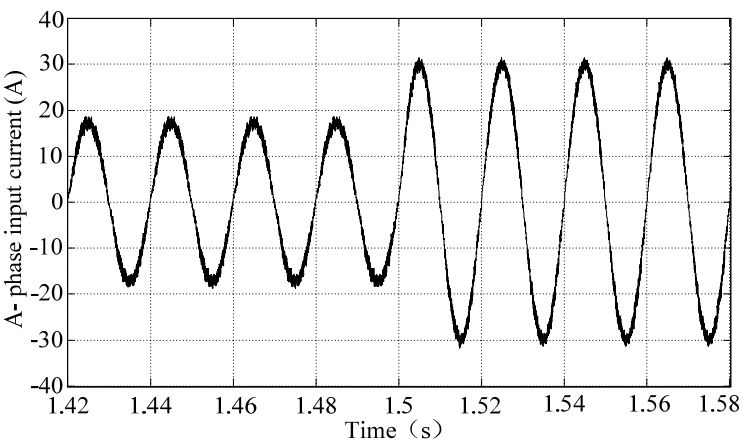

a. Traditional current control strategy

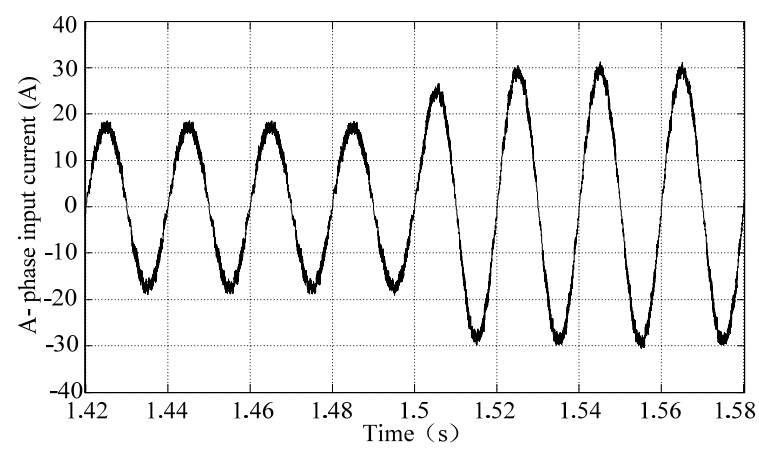

b. Deadbeat current control strategy

Fig.7 A-phase current of the AC side

Fig.5 shows that, under the traditional inner loop current control strategy that based on dq transformation, the DC voltage remain stable at $500 \mathrm{~V}$ at $0.5 \mathrm{~s}$, but under the control of deadbeat current control strategy the DC voltage can be stabilized at $500 \mathrm{~V}$ at $0.15 \mathrm{~s}$; when the load resistance changed suddenly, under the control of traditional current control based on the $\mathrm{dq}$ transformation, the DC voltage drops about $10 \mathrm{~V}$ and after $0.8 \mathrm{~s}$ restore stability at about $500 \mathrm{~V}$, under the control of deadbeat current control strategy the DC voltage drops about $2 \mathrm{~V}$ and after $0.2 \mathrm{~s}$ restore stability at about 500V. From Fig.6, when the load resistance suddenly decreased, the power increased at the DC side and input current increases rapidly at the $\mathrm{AC}$ side, in order to ensure the power balance of the input and output of the rectifier, while the system is still transported in the unit power factor. Fig.7 shows that when the load resistance changed suddenly, dynamic response of deadbeat current control strategy is half cycle faster than the traditional current control strategy based on dq transformation.

\section{CONCLUSION}

In this paper, on the basis of the discrete mathematical model for three-phase PWM voltage source rectifier analysis, designed controllers respectively based on deadbeat current control strategy and traditional current control strategy. Simulation results show that under the control of deadbeat current control strategy, three-phase voltage source PWM rectifier has good steady-state and dynamic performance in stabilizing DC voltage, controlling current of AC side, and rectifier can run under unity power factor of network side and effectively suppress input harmonic current. The control strategy is effective and superior, so it has certain practical value.

\section{REFERENCES}

[1] Mao Hong, Wu Zhaolin. "Study on the Sensorless Current Control Strategy of Three-Phase Voltage-Source PWM Rectifier". Transactions of China Electrotechnical Society. 2001, 16(2): 56-60

[2] Dixon Juan W, ooi Boon Teck. “ Indirect current control of a unity power factor sinusoidal current boost type three- phase rectifier". IEEE Trans. I nd.Electron,1988,35 (4):508-515

[3] Wu R, Dewan S B,Slemon G B.A PWM AC-to-DC converter with fixed switching frequency[J].IEEE Trans. Ind.Appl.,1990,26:880-885

[4] Ooi B T, Salmon J C, Dixon J W, et al. Athree phase controlled current PWM converter with leading power factor[J]. IEEE Trans. Ind. Appl., 1987, IA-23: 78-84

[5] Dixon J W, Kullcarni A B, Nishimato M, et al. Characteristics of a controlled-current PWM rectifier-inverter link[J]. IEEE Trans. Ind. Appl., 1987, IA-23: 1022-1028

[6] Guo Weinong, Duan Shanxu, Chen Jian. Deadbeat Control Inverter Based on DSP[J] .Telecom Power Technologies. 2001,1- 4

[7] Wei Xiaoguang, Tang Guangfu. Discretization Modeling and Simulation Study of HVDC Power Transmission System Based on Voltage Source Converters [J]. Power System Technology. 2006, 30(20):34-39

[8] Amirnaser Yazdani. Modelling and control of the three-level neutral point diode clamped(NPC) converter for high-power application[D]. Canada: University of Toronto, 2005 